\title{
Impact of the use of cadaver on student's ability to pass anatomy examination
}

\author{
Godson Emeka Anyanwu', Anthony Ikemefuna Ugochukwu² \\ ${ }^{1}$ Department of Anatomy, College of Medicine, University of Nigeria, Enugu Campus, Enugu, Nigeria \\ ${ }^{2}$ Department of Anatomy, College of Medicine, Enugu State University of Science and Technology, Enugu Campus, Enugu, Nigeria
}

\begin{abstract}
Objectives: Controversial in the development of anatomical science education is the role of dissection in the teaching of anatomy. Several doubts have been expressed over the usefulness of the use of cadavers in gross anatomy studies. This work was designed to compare the outcomes from a cadaver dissection-based study with a non-cadaver-based study.

Methods: A total of 128 medical students divided into two groups were used for this study. Both groups were required to study the gross anatomy of a given region. While Group A used cadaver dissection and other methods of studying anatomy available in the department, Group B studied with all the materials made available for Group A, but without a cadaver. Both groups undertook the same essay and multiple-choice exams on the region studied.

Results: The mean score for the various parts of the exam noted for Group A was $65 \%$, while that for B was $55 \%$. The percentage number of students with distinction grades in A was 39 while B was 17. In all, $91 \%$ of the students in Group A attained the pass mark while only $63 \%$ from B did.

Conclusion: The students that had a cadaver dissection-based study did better in all aspects of the exams with a significant difference between the mean scores of both groups. Standard deviations were smaller for the group that studied with cadaver in all aspects of the exam.
\end{abstract}

Key words: cadaver dissection; medical education; cadaver-based study

Anatomy 2010; 4: 28-34, (C) 2010 TSACA

\section{Introduction}

In the early days of medical education, the study of gross anatomy was based around cadaveric dissection. ${ }^{1,2}$ This was as a result of the fact that cadaveric dissection was the only available method of three dimensional study of the gross anatomical structures. Between this period and now, many changes have been made in medical school curricula as a result of advances in science, medical diagnostics and the profession of teaching. ${ }^{3}$ One of these changes is the very significant reduction in the time allocated to the teaching of anatomy and also the dissection of cadavers. ${ }^{4,5}$ Also included in these new curricula is the introduction of clinical reasoning, physical examina- tion skills, clinical imagings, diagnostics, use of problembased learning, application of teaching modalities such as use of prosected specimen, models, radiographic images and computer simulations. ${ }^{6,7}$ These trends in medical curricula have brought about fading away of traditional dissection in our medical schools. Many views have been expressed against this current trend. ${ }^{8-10}$

Like other fields of learning that have been marked by development and evolution of communication skills, the quest for new and effective ways of passing anatomical ideas has produced much controversy and disagreement. ${ }^{3,11}$ At the forefront of this controversy is the role of dissection in today's teaching of anatomy. ${ }^{12}$ Patel and 
Moxham $^{10}$ in their work "Attitudes of professional anatomists to curricular changes" categorized the various views on this issue into two major groups; the view of the "traditional anatomists" and that of "the modern anatomists". The traditionalists are those who are presently fighting to maintain the use of cadaveric dissection and the modernists are the ones advocating for the more novel and "modern" ways of teaching anatomy. These new ways, the "modernists" maintain, will express the spatial relationships of the gross features of the body better than cadaveric dissection while still conserving the time which ordinarily would have been wasted in dissection. This argument has raged over the years ${ }^{11,12}$ and some studies have reported these new methods of teaching anatomy to be better in conveying a better understanding of the anatomy course to the students, ${ }^{13-15}$ whereas several other reports have maintained an opposing view. ${ }^{8,16-18}$ Also interesting to note is an intermediate opinion within these two extreme points which is the view that argues for retention of some dissections within the curriculum but inclusion of other complementary methods of delivery of the subject. ${ }^{19}$

We looked at the research designs of some of the previous works and noted the various ways the students making up the sample population for these studies were categorized. In some of these cases some groups of students were made to dissect a particular region while the others were made to study the same region but using prosected bodies. ${ }^{18}$ In another case a group of students actively dissected the cadaver while another group participated by observation of the dissections only. ${ }^{20}$ Some other authors used various student groups which dissected different body regions concurrently and later each group was made to teach the other groups the areas they dissected. We noted that in the various studies above, all the students were actively or passively exposed to the benefits of the cadaver. We have designed a study that will show a clear demarcation between a cadaver-based study and a non-cadaver-based study. By this way, we achieved through a clear separation between students exposed to the cadaver through dissection only and students that never had any contact with the cadaver. With these two major groups in mind we decided to answer the question; is there a difference in outcome between a cadaver-based study and a non-cadaver-based study? It is presently upheld by "modern anatomists" ${ }^{10}$ that cadaver dissection is all about many hours of cutting with excessive contents that prevent students from discerning between what is essential and what is accessory in clinical practice? ? $^{21}$

\section{Materials and Methods}

A total of 128 medical students of Enugu State University of Science and Technology, Enugu, Nigeria, were randomly selected for this study. These were students that were in their first pre-clinical year. The students were divided into two major groups; A and B. Group A was made up of 69 students while B included 59 students. The randomization process of assigning students to the two groups was based on the alphabetical arrangement of the surnames of the selected students in both the male and female lists. The study sample was made up of male to female ratio of 3:2 respectively in both groups. Only students that had undergraduate entry into the class, without any previous exposure to human anatomy or dissection and who had passed the first medical professional examination were qualified for this study. The age distribution of the candidates ranged from 19 to 27 years. Group A was the dissection group and group B was the non-dissection and non-cadaverbased group. Group A was further divided into 8 dissection tables where each of the subgroups were dissected the same areas in their different cadavers. Dissection of upper and lower limbs was done by all the members of group A. All the members of the various tables in this group took turns in dissection and this was done under the supervision of some members of the department. The dissection procedure was the same which was outlined in Cunningham's dissection manual. ${ }^{22}$ In the cadaver-based studies carried out in Group A, the members were not given access to prosected specimens in order to regulate the variables introduced into the work.

Both Groups A and B were evenly exposed to other methods of teaching anatomy in the department which included didactic teaching, textbooks, atlases, models, video tapes and discs, $\mathrm{X}$-ray films, computer programs 
and group discussions. Both groups were taught the anatomy of the upper and lower limbs together. Members of Group B were denied access to the use of the dissection laboratory, studying with prosected specimens or doing any form of cadaver-based study. During the two hourly dissection slots observed in Group A, all the members of Group B, under the supervision of some members of the department gathered in the departmental museum where they had guided revisions on the regions being dissected in Group A, using various other facilities in the department. In both groups the supervisors played the passive role of proffering only answers and clarifications to the student's questions as they arose. The same contact hours with the supervisors and same time of exposure to the different study materials were maintained for the two groups. Peer teaching was encouraged amongst the students of both groups.

At the end of the learning phase of the experiment, the students were assessed using both multiple choice and essay questions. These were basic questions assessing the knowledge of the position, course, relations and functions of some of the structures encountered within the regions studied. Some applied questions on the clinical anatomy of some of these structures were also included. The essay assessment included both long and short answer questions. The short answer questions demanded a brief knowledge of the subject while the long answer questions, demanded detailed explanations of the subject. The scoring in this section was done by only one of the examiners to reduce intra-marker variability. The multiple choice questions (MCQ) included a total of 100 questions. Three types of MCQ formats were used. The first MCQ format used was the stem type. This was made up of five options with only one correct option. The second MCQ format was the extended matching questions (EMQ). The third format was the TRUE OR FALSE format. There was no negative scoring in the marking of the MCQs . The MCQs were also manually marked by the authors. In the marking of both essay and MCQs, the examiners were blind to the group to which each of the scripts belonged. In carrying out this research, efforts were made to ensure there was no mixing of the two groups through taking of attendance in both groups for each of the two hours that the students did different things.

\section{Statistical analysis}

The performance of students in the various aspects of the examinations by the two groups were compiled and analyzed using the SPSS package for data analysis.

\section{Results}

Table 1 gives a statistical summary of the various parts of the exam. The various levels of performance of the students were categorized in Table 2 following the guidelines of the Nigerian University Commission and also the Nigerian Medical and Dental Council. By this, Failure grades are scores below 50\%, Pass grades are scores from $50 \%$ and above and Distinction grades are grades from $70 \%$ and above. A Pearson correlation analysis was performed to assess the linear relationship between the scores from MCQs and the essay questions and this was significant $(\mathrm{r}=0.62, \mathrm{p}=0.01)$.

Table 1

Summary of the scores in the various aspects of the exam for the two groups

\begin{tabular}{lllllll}
\hline & $\begin{array}{c}\text { Obj. } \\
\text { GRP A }\end{array}$ & $\begin{array}{c}\text { Obj. } \\
\text { GRP B }\end{array}$ & $\begin{array}{c}\text { Essay } \\
\text { GRP A }\end{array}$ & $\begin{array}{c}\text { Essay } \\
\text { GRP B }\end{array}$ & $\begin{array}{c}\text { Total } \\
\text { GRP A }\end{array}$ & $\begin{array}{c}\text { Total } \\
\text { GRP B }\end{array}$ \\
\hline Mean & 68.90 & 56.73 & 61.16 & 52.92 & 65.03 & 54.82 \\
Median & 74.00 & 58.00 & 61.00 & 53.00 & 67.50 & 54.20 \\
Mode & 80.00 & 49.00 & 54.00 & 49.00 & 59.50 & 44.50 \\
Std. Dev. & 12.24 & 13.90 & 11.42 & 12.27 & 10.66 & 11.94 \\
Minimum & 20.00 & 26.00 & 35.00 & 26.00 & 28.00 & 29.50 \\
Maximum & 86.00 & 82.00 & 85.00 & 77.00 & 79.50 & 76.50 \\
\hline
\end{tabular}


Table 2

Frequency distribution of the performances of the students in the various aspects of the exams

\begin{tabular}{|c|c|c|c|c|}
\hline \multirow{2}{*}{$\begin{array}{l}\text { Categories of } \\
\text { performances }\end{array}$} & \multicolumn{2}{|c|}{ Frequency } & \multicolumn{2}{|c|}{ Frequency in percentage } \\
\hline & GRP A & GRP B & GRP A & GRP B \\
\hline Obj. scores > 70 & 41 & 14 & 59 & 24 \\
\hline Essay scores $>70$ & 17 & 5 & 25 & 8 \\
\hline \multicolumn{5}{|l|}{ Obj. scores > 50} \\
\hline But $<70$ & 24 & 34 & 35 & 58 \\
\hline \multicolumn{5}{|l|}{ Essay scores > 50} \\
\hline But $<70$ & 44 & 30 & 64 & 51 \\
\hline Total scores > 70 & 27 & 10 & 39 & 17 \\
\hline \multicolumn{5}{|l|}{ Total scores > 50} \\
\hline But $<70$ & 36 & 27 & 52 & 46 \\
\hline Total score $<50$ & 6 & 22 & 9 & 37 \\
\hline Obj. scores > 50 & 65 & 39 & 94 & 66 \\
\hline Essay scores > 50 & 61 & 35 & 88 & 59 \\
\hline Total scores > 50 & 63 & 37 & 91 & 63 \\
\hline
\end{tabular}

Table 1 showed higher mean percentage scores for Group A students than Group B students. In Group A, $59 \%$ of students achieved a distinction, compared with $24 \%$ in Group B. In all parts of the exams, higher scores were attained by students of Group A.

The various parts of the exams in Group A when correlated with complementary part of the exam in Group B using Pearson correlation showed no significant correlation. Table 3 gave a summary of the significant differences noted between the mean performances of both groups in all parts of the exam using the unpaired sample t-test.

\section{Discussion}

The results of the present study suggest that cadaverbased-study enhances students' understanding of gross anatomy and their ability to pass anatomy exams. The students that were exposed to a cadaver-based study, in our own case through dissection, performed better than the other students in both the essay and multiple-choice exams. The number of students that had a distinction grade in the non-dissection group was more than doubled in the dissection group. Whereas $37 \%$ of the students failed in the non-dissection group, only $9 \%$ failed

Table 3

The results of the comparison of some paired means using paired sample T-test

\begin{tabular}{|c|c|c|c|c|c|c|c|c|}
\hline & \multirow{3}{*}{ Mean } & \multicolumn{2}{|c|}{ Paired difference } & \multirow{2}{*}{\multicolumn{2}{|c|}{$\begin{array}{l}95 \% \text { Confidence } \\
\text { interval of } \\
\text { the difference }\end{array}$}} & \multirow[b]{3}{*}{$\mathbf{t}$} & \multirow[b]{3}{*}{ df } & \multirow{3}{*}{$\begin{array}{c}\text { Sig. } \\
\text { (2-tailed) }\end{array}$} \\
\hline & & Std. Dev. & Std. Error. & & & & & \\
\hline & & & Mean & Lower & Upper & & & \\
\hline \multirow[t]{2}{*}{ Pair 1} & Obj. Gp. A & & & & & & & \\
\hline & Obj. Gp. B & 12.0847 & 18.7876 & 7.1887 & 16.9808 & 4.941 & 58 & .000 \\
\hline \multirow[t]{2}{*}{ Pair 2} & Essay Gp. A & & & & & & & \\
\hline & Essay Gp. B & 7.9492 & 16.0080 & 3.7774 & 12.1209 & 3.814 & 58 & .000 \\
\hline \multirow[t]{2}{*}{ Pair 3} & Total Gp. A & & & & & & & \\
\hline & Total Gp. B & 10.0169 & 15.5682 & 5.9598 & 14.0741 & 4.942 & 58 & .000 \\
\hline
\end{tabular}

95\% Confidence interval 
the exam in the dissection group. With the significant difference noted between the performances of both groups, one can confidently state that any program designed in the medical curriculum with little or no exposure of students to the act of learning anatomy through dissection and other cadaver-based approaches, will not automatically bring out the best from the students.

It has been argued and we agree that no matter how sophisticated a software package maybe, images are still projected in a two dimensional screen, whereas a cadaver-based study enhances a 3-dimensional image of human anatomy. ${ }^{23}$ It is the opinion of many authors ${ }^{3,5,16,24}$ that cadaver dissection-based study provides the students with a definitive and authoritative source that enables the students to master structural knowledge and to develop active learning skills. In a similar study Patel and Moxham $^{10}$ noted a better performance by students exposed to either dissection or prosected cadavers than students that had no contact with the cadaver.

This finding is contrary to the result of Jones et al..$^{25}$ who in a similar experiment, reported better academic performance for students that had a non-cadaver-based study than the students that carried out dissection.

Beyond preparing the students for better academic performance as has been noted in this work, a number of reports have been documented which have presented various other advantages of cadaver-based study. Amadio $^{26}$ in the editorial "Reaffirming the importance of dissection" reported the traditional dissection experience as the only tool that will give the students an appreciation of the natural variety of human structure as opposed to "virtual cadavers." This report presented dissection as one of the critical elements in the development of the physician, particularly in the issue of coming to terms with mortality. Moore ${ }^{27}$ in his work "To dissect or not to dissect" outlined the various disadvantages associated with non-cadaver-based curriculum. Some of these were anatomical features and pathologies not easily demonstrated using computer aided programs, lack of development of some of the basic qualities vital to clinical practice such as practical skills, ethics and confidentiality based on respect for humanity of the cadaver which are developed as a result of the impact of the privilege of dissection. With these advantages in mind coupled with the result of this study and similar results from other studies, it is our opinion that the impression that cadaver dissection is all about many hours of cutting, with excessive content that prevents students from discerning between what is essential and what is accessory in clinical practice as has been suggested by some authors is wrong. The long hours involved in dissection have been and are still part of the process of the making of the physician as has been enumerated above. Shaw-Dunn ${ }^{28}$ commenting on this issue, advised for measures to reduce the length of time given to dissection. Presently a cadaver-based alternative approach; prosection has long been introduced and accepted in many institutions. This method has been reported by a number of authors to have the same if not better effectiveness as dissection while still reducing the long hours that would have been spent on dissection. ${ }^{16,29}$ The issue of the large volume of content involved in dissection could be taken care of by the use of concise standard dissection manuals and also by breaking down the goals that should be achieved for each dissection session and properly supervising the activities of the students during these sessions, to discourage unnecessary deviations and waste of precious time.

The use of computer aided programs, simulators, audiovisual and radiographic images etc in the teaching of gross anatomy in our view should be complementary to cadaver-based study. It became an issue when these new technologies that were to complement use of cadaver-based studies started replacing the use of cadavers for learning. Amadio, the president of AACA as at the time of his report ${ }^{26}$ made statement; "The AACA expresses a concern when students are expected to learn anatomy in the absence of dissection or, alternatively, through careful examination of prosected specimen." We are concerned about the quality of anatomy being passed to this new generation of students and the future of anatomy if such methods of learning are not retained. Nnodim, ${ }^{29}$ in 
1990 provided evidence that students who learnt gross anatomy through prosection performed better that those that dissected. But 5 years later, in a follow up experiment ${ }^{30}$ when the students were invited for a retest on the same exam, reported a reversal in the performance of both groups. In their conclusion, they reported a higher level of attrition in the knowledge of anatomy for the students that learnt from prosection. The longer term retention of anatomical understanding is not yet known for the students in our study. The fear is if this level of attrition could be recorded for a method accorded with being as good, if not better than dissection, what will happen if such follow up studies are done for these students, which have been taught gross anatomy without cadaver. We do not think the argument that the decreasing time allotted to cadaver dissection and the use of the new innovations as the primary tools in teaching anatomy, is borne out of resentment but out of fear for the quality of clinical students and medical professionals that will graduate through such programs and also on the future of anatomy education.

Based on the results of this research, it is our view that a decline in the quality of gross anatomy passed to our new generation of medical students and a loss in the importance of anatomy as one of the basic pillars of medical education are inevitable if we continue to run a medical curriculum with little or no time for cadaverbased study, especially dissection of the cadaver. Although the use of cadaver-based study is not without its own challenges such as the availability and sourcing of cadavers, emotional impacts on some students on exposure to these cadavers, health and safety issues associated with the use of cadaver, removing it from the curriculum in our view should not be the solution. We rather recommend that efforts be channeled towards overcoming or reducing these challenges. The importance of some of the new innovations and technologybased teaching methods cannot be over-emphasized as we noted in the number of students who passed in the non-dissection group. We recommend that they be used as complementary measures to cadaver-based studies in the teaching of gross anatomy to medical students.

\section{References}

1. Persaud TVN. The Early History of Human Anatomy: From Antiquity to the Beginning of the Modern Era. Springfield, Ill: Thomas Books; 1984.

2. Singer C. A Short History of Anatomy from the Greeks to Harvey. New York, NY: Dover; 1957.

3. Vasquez R, Riesco JM, Carretero J. Reflections and challenges in the teaching of human anatomy at the beginning of the 21 st century. Eur F Anat 2005; 9: 111-5.

4. McKeown PP, Heylings DJ, Stevenson M, McKelvey, KJ, Nixon JR, McCluskey DR. The impact of curricular change on medical students' knowledge of anatomy. Med Educ 2003; 37: 954-61.

5. Aziz MA, McKenzie JC, Wilson JS, Cowie RJ, Ayeni SA, Dunn BK. The human cadaver in the age of biomedical informatics. Anat Rec (New Anat) 2002; 269: 20-32.

6. Topp K. Prosection vs. dissection, the debate continues: rebuttal to Granger. Anat Rec (Part B: New Anat) 2004; 281B: 12-14.

7. Leung KK, Lu KS, Huang TS, Hsieh BS. Anatomy instruction in medical schools: connecting the past and the future. Adv Health Sci Educ Theory Pract 2006; 11: 209-15.

8. Parker LM. Anatomical dissection: why are we cutting it out? Dissection in an undergraduate teaching. ANZ 7 Surg 2002; 72: 910-2.

9. Heylings DJ. Anatomy 1999-2000: the curriculum, who teaches it and how? Med Educ 2002; 36: 702-10.

10. Patel KM, Moxham BJ. Attitudes of professional anatomists to curricular change. Clin Anat 2006; 19: 132-41.

11. Winklemann A. Anatomical dissection as a teaching method in medical school: a review of the evidence. Med Educ 2007; 41: 15-22.

12. Guttman GD, Drake RL, Trelease RB. To what extent is cadaver dissection necessary to learn medical gross anatomy? A debate forum. Anat Rec B New Anat 2004; 281: 2-3.

13. Granger N. Dissection laboratory is vital to medical gross anatomy education. Anat Rec B New Anat 2004; 281: 6-8.

14. McLachlan J. New path for teaching anatomy: living anatomy and medical imaging vs. dissection. Anat Rec B New Anat 2004; 281: 4-5.

15. Pawlina $W$, Lachman N. Dissection in learning and teaching gross anatomy: rebuttal to McLachlan. Anat Rec B New Anat 2004; 281: 9-11.

16. Johnson JH. Importance of dissection in learning anatomy: personal dissection versus peer teaching. Clin Anat 2002; 15: 38-44.

17. Jones LS, Paulman LE, Terracio L. Does cadaver dissecting by students affect their gross anatomy practical exam performance? FASEB 7 1999; 13: 770-4.

18. Yeager VL. Learning gross anatomy: dissection and prosection. Clin Anat 1996; 9: 57-9.

19. McLachlan JC, Bligh J, Bradley P, Searle J. Teaching anatomy without cadavers. Med Educ 2004; 38: 418-24. 
20. Bernard GR. Prosection demonstrations as substitutes for the conventional human gross anatomy laboratory. 7 Med Educ 1972; 47: 724-8.

21. Reidenberg JS, Laitman JT. The new face of gross anatomy. Anat Rec B New Anat 2002; 269: 81-8.

22. Romanes GJ. Cunningham's Manual of Practical Anatomy. 15th ed. Oxford: Oxford University Press; 1986.

23. Rizzolo LJ, Aden M, Stewart WB. Correlation of web usage and exam performance in a human anatomy and development course. Clin Anat 2002; 15: 351-5.

24. O'Malley CD. Andrea Vesalius of Brussels. Los Angeles: University of California Press; 1964.
25. Jones NA, Olafson RP, Sutin J. Evaluation of a gross anatomy program without dissection. 7 Med Educ 1978; 53: 198-205.

26. Amadio PC. Reaffirming the importance of dissection. Clin Anat 1996; 9: 136-7.

27. Moore NA. To dissect or not to dissect? Anat Rec 1998; 253: 8 -9.

28. Shaw-Dunn J. Follow the radical road: comment on R.L.M Newell's paper. Clin Anat 1995; 8: 131-3.

29. Nnodim JO. Learning human anatomy: by dissection or from prosection? Med Educ 1990; 24: 389-97.

30. Nnodim JO, Ohanaka EC, Osuji CU. A follow up comparative study of two modes of learning human anatomy: by dissection and from prosections. Clin Anat 1996; 9: 258-62.

Correspondence to: Godson Emeka Anyanwu, PhD Department of Anatomy, College of Medicine University of Nigeria, Enugu Campus, Enugu State, Nigeria e-mail: anyanwugemeks@yahoo.com

Conflict of interest statement: No conflicts declared. 